\title{
0 ensino de procedimentos de política de indexaçãa na perspectiva do conhecimento organizacional: uma proposta de programa para a educação à distância do bibliotecário
}

\begin{tabular}{|c|c|}
\hline \multirow{3}{*}{ Milena Polsinelli Rubi } & 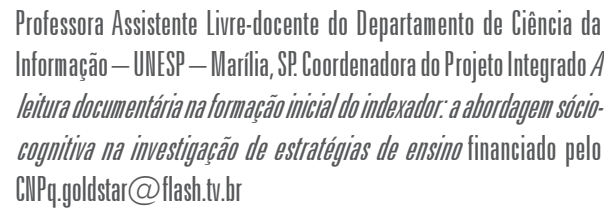 \\
\hline & \\
\hline & $\begin{array}{l}\text { Douttoranda do Curso de Pós-Graduação em Ciência da Informação - UNESSP, } \\
\text { Marilia, SP. Bolsista CAPES.(18) 225-1898. mprubi@igy.com.br }\end{array}$ \\
\hline
\end{tabular}

A política de indexação deve ser constituída de estratégias que permitam o alcance dos objetivos de recuperação do sistema de informação. $O$ indexador tem a função primordial de compreender o documento ao realizar uma análise conceitual que represente adequadamente seu conteúdo. Utilizando a leitura como evento social/protocolo verbal em grupo, nosso objetivo é contribuir com a literatura sobre política de indexação e apresentar propostas de ensino de política de indexação direcionadas a alunos de graduação e pós-graduação, além de uma experiência de educação à distância com vistas à formação do bibliotecário em serviço. Os resultados obtidos demonstraram que a metodologia pode ser utilizada por sistemas de informação para que se tenha acesso ao conhecimento do indexador. Conclui que o indexador deve ser o alvo de investimento dos sistemas de informação e sugere aos sistemas de informação que a experiência do indexador também seja utilizada como parâmetro para política de indexação.

Palavras-chave: Política de indexação; Indexador; Manual de indexação; Sistema de recuperação da informação; Leitura como evento social; Conhecimento organizacional; Prática de ensino de política de indexação; Educação à distância. 


\section{Introdução}

A política de indexação dentro de um sistema de informação deve ser entendida como uma filosofia pertinente aos objetivos de recuperação da informação e não somente como uma lista de procedimentos a serem seguidos durante a realização da indexação. Isso nos leva a refletir sobre a indexação não somente do ponto de vista do processo, da operação técnica, mas sim da biblioteca como uma organização, pois a tarefa da indexação só terá sentido uma vez norteada e respaldada por essa filosofia. Dessa maneira, estaremos inserindo a indexação no contexto administrativo da biblioteca e não a relegando a um contexto meramente de cunho técnico, dessa maneira, valorizando-a.

Os sistemas de informação são compostos por partes interligadas (inserção de documentos, classificação, catalogação, indexação etc.) com objetivo comum de disponibilizar a informação da melhor maneira possível. Nota-se, portanto, que a indexação e, por conseguinte, sua política, é uma das partes desses sistemas e, como tal, deve integrar também o planejamento global dos sistemas de informação como um parâmetro de sua administração no contexto gerencial.

Sob o ponto de vista do sistema de recuperação da informação, a indexação é reconhecida com sua parte mais importante dentro dos procedimentos realizados para o tratamento da informação, pois condiciona os resultados das estratégias de busca. Nesse contexto, o indexador tem como função compreender o documento ao realizar uma análise conceitual que represente adequadamente seu conteúdo, de modo que ocorra correspondência entre o índice e o assunto pesquisado pelo usuário. Para isso, existem os manuais de indexação que devem refletir a política de indexação do sistema de informação e a realidade de trabalho do indexador.

Devido à literatura escassa sobre política de indexação, procurou-se obter por meio da experiência do indexador mais subsídios sobre o tema.

Utilizando como metodologia a leitura como evento social/protocolo verbal em grupo, nosso objetivo é contribuir, de forma teórica, com a literatura sobre política de indexação.

De maneira prática, apresentamos algumas propostas de ensino de política de indexação direcionadas a alunos de graduação e pós-graduação, além de uma experiência de educação à distância com vistas à formação do bibliotecário em serviço.

Essa experiência é representada pelo curso à distância Política de indexação em sistemas de informação, ministrado a bibliotecários indexadores das três universidades estaduais paulistas - Universidade de São Paulo USP - ; Universidade Estadual Paulista - UNESP - e Universidade Estadual de Campinas - UNICAMP - integrantes do Sistema CRUESP/Bibliotecas.

\section{Política de indexação}

No Brasil, em 1985, Marília Vidigal Carneiro em seu artigo, atualmente considerado um clássico para os estudos sobre política de indexação, apontou os principais elementos de política de indexação e as variáveis a serem consideradas para o seu estabelecimento em um sistema de informação. Desde então, as pesquisas sobre política de indexação ficaram estagnadas, sendo 
retomadas por Guimarães (2000) e Rubi (2003; 2004).

Em âmbito internacional, podemos destacar o trabalho do espanhol Cubillo (2000) que trata sobre as mudanças e continuidades das organizações de gestão do conhecimento. $\bigcirc$ referido autor ressalta que na sociedade da informação o tratamento documentário assume uma dimensão estratégica, uma vez que o documento é o representante ou substituto das idéias, e por isso a importância e urgência da implantação de política de indexação. No nosso ponto de vista, entendemos que um dos motivos pelo qual os estudos sobre política de indexação ficaram defasados por I 5 anos diz respeito, principalmente, ao modo como a indexação é vista dentro da biblioteca: muitas vezes, somente como um processo técnico que não necessita de procedimentos sistematizados para identificação de assuntos, somente de uma leitura rápida para identificar e extrair os termos para representar o conteúdo. Desse modo, a implantação de uma política de indexação é considerada desnecessária.

É preciso que as bibliotecas percebam a importância da indexação em todo o ciclo documentário, considerando-a como parte da administração, compreendendo que a indexação necessita de parâmetros que guiem os indexadores no momento de tomadas de decisões minimizando subjetividade e incertezas durante o processo de indexação, reconhecendo, portanto, a importância em se implantar uma política de indexação.

Além disso, consideramos a política de indexação, em tempos de inovações tecnológicas, deixou de ser localizada para se tornar também globalizada. Devemos isso ao fato de que a automação das bibliotecas permitiu que os catálogos, antes locais e restritos a determinada comunidade, se tornassem disponíveis através da Internet, atravessando fronteiras geográficas. No nosso ponto de vista, essa visibilidade do catálogo fez com que fosse necessária a adoção de critérios de qualidade para a recuperação da informação, sendo a política de indexação um deles.

De acordo com Carneiro (1985, p. 22 I) uma política de indexação

[...] deve servir como um guia para tomada de decisões, deve levar em conta os seguintes fatores: características e objetivos da organização, determinantes do tipo de serviço a ser oferecido; identificação dos usuários, para atendimento de suas necessidades de informação e recursos humanos, materiais e financeiros, que delimitam o funcionamento de um sistema de recuperação de informações.

Lembrando que a política de indexação deve estar inserida no contexto administrativo da biblioteca, Carneiro (1985) apresenta os seguintes requisitos imprescindíveis ao planejamento de um sistema de recuperação de informação ao se estabelecer uma política de indexação:

- $\quad$ a identificação da organização à qual estará vinculada ao sistema de indexação (contexto);

- $\quad$ a identificação da clientela a que se destina o sistema (destinatário);

- $\quad$ os recursos humanos, materiais e financeiros (infra-estrutura). Podemos considerar, portanto, que a política de indexação está inserida em dois contextos complementares: 
a) contexto sociocognitivo do indexador: a política de indexação, as regras e procedimentos do manual de indexação, a linguagem documentária para representação e mediação da linguagem do usuário e os interesses de busca dos usuários;

b) contexto físico de trabalho do indexador e dos gerentes - o sistema de informação. (FUJITA, 2003).

Kobashi (1994, p. 17-19) destaca que as atividades de coleta, tratamento e difusão da informação não são neutras, pois são realizadas dentro de instituições informacionais e, por essa razão, é necessário que se faça uma análise rigorosa do contexto no qual se insere o sistema documentário. Assim, a autora também esclarece que a política de tratamento e recuperação da informação está condicionada a características dos sistemas documentários:

- $\quad$ necessidades do usuário;

- $\quad$ instituição onde se desenvolve

- domínio tratado;

- $\quad$ recursos humanos, físicos e financeiros disponíveis;

- $\quad$ produtos e serviços;

- relação custo/desempenho.

Nesse contexto também, segundo Guimarães (2000), o estabelecimento de uma política de indexação contribuirá para que o usuário e o documento deixem de ser sujeito e objeto para se tornarem dois sujeitos que interagem, uma vez que o usuário estará sempre recriando o documento e, por conseqüência, alimentando novamente o sistema.

Conforme afirmado anteriormente, a política de indexação não deve ser vista como uma lista de procedimentos a serem seguidos, mas sim como uma filosofia a ser adotada pelo sistema de recuperação da informação. No entanto, segundo Carneiro (1985), os seguintes elementos devem ser considerados na elaboração de uma política de indexação:

a) Cobertura de assuntos: assuntos centrais e periféricos cobertos pelo sistema;

b) Seleção e aquisição dos documentos-fonte: extensão da cobertura do sistema em áreas de assunto de seu interesse e a qualidade dos documentos, incluídos no sistema;

c) Processo de indexação:

c. I Nível de exaustividade: todos os assuntos apresentados no documento são identificados durante a indexação e traduzidos em uma linguagem documentária; 
c.2 Nivel de especificidade: somente os assuntos realmente tratados no documento são identificados, de maneira específica;

c.3 Escolha da linguagem: a linguagem de indexação afeta o desempenho de um sistema de recuperação de informação tanto na estratégia de busca (estabelece a precisão com que o técnico de busca pode descrever os interesses do usuário) quanto na indexação (estabelece a precisão com que o indexador pode descrever o assunto do documento). Portanto, a partir de estudos do sistema, deve-se optar entre linguagem livre ou linguagem controlada e linguagem pré-coordenada ou pós-coordenada;

c.4 Capacidade de revocação e precisão do sistema: exaustividade, revocação e precisão estão relacionadas. Quanto mais exaustivamente um sistema indexa seus documentos, maior será a revocação (número de documentos recuperados) na busca e, inversamente proporcional, a precisão será menor;

d) Estratégia de busca: deve-se decidir entre a busca delegada ou não;

e) Tempo de resposta do sistema;

f) Forma de saída: é o formato em que os resultados da busca são apresentados. Tem grande influência sobre a tolerância do usuário quanto à precisão dos resultados. Deve-se verificar qual a preferência do usuário quanto à apresentação dos resultados;

g) Avaliação do sistema: determinará até que ponto o sistema satisfaz as necessidades dos usuários.

Guimarães (2000, p. 55) lembra que Carneiro (1985, p. 55) apresenta muitos dos elementos contemplados por Foskett (1973) e ressalta a importância de outros três aspectos apresentados pelo referido autor como complementares ao estudo sobre política de indexação. São eles:

a) Capacidade de consulta a esmo (browsing): torna-se necessário pensar a respeito da interface dos sistemas de busca, revelando, de maneira fácil e direta, a estrutura temática que os organiza;

b) Garantia literária (literary warrant): diz respeito a linguagem de indexação, suas representações de conceitos realmente utilizados pela comunidade usuária em questão;

c) Formação do indexador: em termos de conhecimento das áreas de assunto dos documentos; da metodologia de indexação; das características da linguagem documentária e de suas habilidades lingüísticas.

Guimarães (2000, p. 54-55) acrescenta aos elementos compilados por 
informação quanto à:

- Cobertura de assuntos: aspectos como a conversão retrospectiva de dados e a compatibilidade de linguagem de indexação entre integrantes de um mesmo sistema cooperativo;

- $\quad$ Seleção e aquisição de documentos-fonte: aliar procedência (especialmente no que diz respeito a sites), ao custo, à língua etc.

Reconhecendo a importância que a política de indexação tem ao permear todo o processo do ciclo documentário, desde a coleta da informação até sua recuperação e disseminação, torna-se necessário que ela esteja descrita de maneira clara e objetiva e ao alcance de todos aqueles que contribuem para o desenvolvimento desse ciclo dentro do sistema de informação. Sobre isso, Guimarães (2000, p. 55-56) afirma que

[...] uma política só poderá ter continuidade e aperfeiçoamento no decorrer dos anos se devidamente registrada em documentos, de modo a que se possa ter clareza (independentemente dos elementos humanos) do conjunto de decisões tomadas, suas razões e seu contexto.

Em razão disso, consideramos que a política de indexação de um sistema de informação pode ser observada por meio de diagnósticos de infra-estrutura física, de serviços e de recursos humanos como também por meio de sua documentação oficial, como o manual de indexação.

Responsável pelo processo de indexação, o indexador realiza a análise de um texto com fins de indexação. Essa análise, segundo Fujita (1999), está diretamente vinculada com sua concepção de análise adquirida através de sua formação educacional e da política de indexação do sistema onde está inserido. Dessa maneira, podemos afirmar que o manual de indexação para o indexador deve ser um instrumento real de trabalho e norteador dos princípios de indexação adotados pelo sistema de informação a fim de que seja garantida a consistência na indexação.

Em estudos realizados (RUBI, 2000; FUJITA, 2003; RUBI, 2004), observamos a realidade de bibliotecas que trabalham com áreas específicas do conhecimento, fazendo parte de sistemas de informação (energia nuclear; odontologia; agricultura) e também aquelas que não participam deste tipo de sistema (medicina; direito).

Notamos que os problemas enfrentados pelos bibliotecários destas instituiç̧̃̃es são os mesmos, independente do tamanho e da área de assunto coberta pela instituição. Eles dizem respeito principalmente aos procedimentos de indexação; ao manual de indexação, muitas vezes inexistente; à falta de política de indexação; à atualização da linguagem documentária; à utilização eficiente de software; à capacitação dos usuários e à falta de um grupo de estudos sobre indexação. Devido a essas dificuldades, à escassa literatura sobre política de indexação e à importância da indexação sob o ponto administrativo e gerencial da biblioteca, procuramos novos caminhos através da cultura e do conhecimento organizacional, uma vez que um sistema de informação não deixa de ser uma organização, e pretendemos transpor essa realidade administrativa para os serviços de recuperação dos sistemas de informação. 


\section{O conhecimento organizacional para política de indexação em sistemas de recuperação da informaçã̃o}

Um sistema de informação pode ser considerado um tipo de empresa que, geralmente, não visa lucro direto, mas agrega valor à informação ao adquiri-la e processá-la tecnicamente de forma a torná-la disponível. Portanto, de maneira mais ampla, podemos considerar o sistema de informação como uma organização. Sob esse ponto de vista, Tamayo (1998), que trabalha com estudos sobre cultura organizacional, esclarece que existem duas abordagens principais que podem ser utilizadas no estudo dos valores organizacionais: a partir dos documentos oficiais da empresa e a partir de observações sobre como os valores são percebidos pelos empregados. No nosso caso, elementos de política de indexação são os valores peculiares de cada sistema de informação que estão expressos oficialmente em manuais de indexação e expressam a visão do dirigente sobre como deve proceder todos os centros subordinados ao sistema de informação.

Esses valores existentes nos documentos oficias da organização foram observados por meio dos manuais de indexação, documentos oficias dos sistemas de informação, onde estão descritos formalmente os elementos de política de indexação, os valores orientadores do sistema (RUBI; FUJITA, 2003). Convém esclarecer que não é de nosso interesse estudar cultura organizacional dentro do sistema de informação sob a perspectiva da administração. Mas, comparativamente, é o caso dos manuais de indexação dos sistemas de informação nos quais se verificaram as regras/diretrizes que norteiam o trabalho dos indexadores dos sistemas de informação.

Enveredando ainda pela área da administração, encontramos também os estudos a respeito do conhecimento tácito e do conhecimento explícito, objetos de estudos da gestão do conhecimento e que, por definição, atende aos nossos interesses de pesquisa.

Nonaka e Takeuchi ( 1997, p. 65) explicam que

A criação do conhecimento organizacional deve ser entendida como um processo que amplia organizacionalmente o conhecimento criado pelos indivíduos, cristalizando-o como parte da rede de conhecimento da organização. (NONAKA; TAKEUCHI, 1997, p. 65, grifo dos autores).

Utilizando definições estabelecidas por Michael Polanyi ( 1966), Nonaka e Takeuchi (1997, p. 65) distinguem dois tipos de conhecimentos complementares: conhecimento tácito e conhecimento explícito.

conhecimento tácito é pessoal, específico ao contexto e, assim difícil de ser formulado e comunicado. $\bigcirc$ conhecimento explícito refere-se ao conhecimento transmissível em linguagem formal e sistemática. (NONAKA; TAKEUCHI, 1997, p. 65).

Nota-se, portanto, que identificar e compartilhar conhecimento explícito não é tarefa difícil, pois este é claro e estruturado podendo ser representado facilmente por meio de procedimentos, linguagem, documentos, bancos de 
dados etc. A maior dificuldade está na identificação e compartilhamento do conhecimento tácito, o que exige um intenso contato pessoal, pois se refere ao conhecimento subjetivo, às experiências, habilidades e intuições acumuladas pelo indivíduo ao longo de sua vida.

Nonaka e Takeuchi ( 1997) partem do pressuposto que o conhecimento é criado por meio da interação entre o conhecimento tácito e o conhecimento explícito. Por isso, estabelecem quatro modos diferentes de conversão do conhecimento:

- $\quad$ socialização: de conhecimento tácito em conhecimento tácito;

- $\quad$ externalização: de conhecimento tácito em conhecimento explícito;

- combinação: de conhecimento explícito em conhecimento explícito;

- $\quad$ internalização: de conhecimento explícito para conhecimento tácito.

A socialização, segundo os referidos autores (1997, p. 69) "[...] é um processo de compartilhamento de experiências e, a partir daí, da criação do conhecimento tácito como modelos mentais ou habilidades compartilhadas."

A externalização é um processo de criação do conhecimento perfeito, na medida em que o conhecimento tácito se torna explícito, expresso na forma de metáforas, analogias, conceitos, hipóteses ou modelos. (NONAKA;TAKEUCHI, 1997, p. 7I).

A combinação, para os referidos autores, é um processo de sistematização de conceitos em um sistema de conhecimento em que os indivíduos trocam e combinam conhecimentos através de documentos, reuniões, conversas ao telefone ou redes de comunicação computadorizadas.

"Finalmente, a internalização é o processo de incorporação do conhecimento explícito no conhecimento tácito. Está relacionada ao aprender fazendo." (NONAKA; TAKEUCHI, 1997, p. 77).

Convém ressaltar aqui o alerta que os autores fazem sobre a necessidade da verbalização e diagramação do conhecimento sob a forma de documentos, manuais ou histórias orais para que o conhecimento explícito se torne tácito, para que a documentação ajude os indivíduos a internalizarem suas experiências, aumentando seu conhecimento tácito e para facilitar a transferência do conhecimento explícito para as outras pessoas, ajudando-as a vivenciar a experiência dos outros. Sobre isso, Nonaka e Takeuchi (1997, p. 83) explicam que "A função da organização no processo de criação do conhecimento é fornecer contexto apropriado para facilitação das atividades em grupo e para a criação e acúmulo de conhecimento em nível individual."

Portanto, pode-se afirmar que o conhecimento explícito dentro do sistema de informação é composto por sua documentação oficial e que, especificamente no caso do serviço de indexação, por seu manual de indexação. Já o conhecimento tácito é aquele inerente a cada 
indivíduo que atua no sistema de informação, como o gerente e o próprio indexador. É esse conhecimento que nos interessa observar, por meio da leitura como evento social/protocolo verbal em grupo, pois nem sempre o que está descrito nos documentos oficiais (manual de indexação) é praticado pelos funcionários (indexadores). Além disso, a utilização da metodologia propiciará, de acordo com os autores citados, um contexto apropriado para a reunião de indexadores e gerentes para o desenvolvimento de uma atividade em grupo.

Devemos lembrar, porém, que os pressupostos teóricos referentes aos conceitos de externalização, socialização, combinação e internalização descritos por Nonaka e Takeuchi (1997) dentro da área de cultura organizacional não apresentam novidade por si mesmos, uma vez que, inseridos no contexto de evento social de leitura/protocolo verbal em grupo (reunião de pessoas para o desenvolvimento de uma atividade em grupo) ecoam as idéias preconizadas por Vygotsky ( 1981 apud NARDI, 1999) e disseminadas por seus seguidores.

Com ênfase no contexto escolar, Vygotsky (NARDI, 1999, p. 27) apresenta sua noção de zona de desenvolvimento proximal (ZDP). Ela concorre para o desenvolvimento do indivíduo ao oferecer um elemento importante para a compreensão sobre como ocorre a interação ensinoaprendizagem/desenvolvimento: as situações que criam contexto para aprendizagem, para o desenvolvimento, são as que envolvem interações assimétricas entre um aprendiz e um indivíduo mais experiente. Portanto, para este trabalho, pode-se afirmar que, segundo os pressupostos Vygotsky (NARDI, 1999) e de seus seguidores, a interação propicia a externalização, a socialização e a combinação, uma vez que os indivíduos participantes estão reunidos com objetivo de construir conhecimento a partir das discussões suscitadas pelo texto e por outros participantes. A internalização também ocorre, porém, de acordo com Vygotsky (NARDI, 1999) é um fenômeno em que o sujeito internaliza o conhecimento adquirido na interação com outros participantes, apropria-se dele e passa a agir e/ou pensar como o outro. No nosso caso, devemos adiantar que não foi possível verificar essa apropriação de conhecimento por qualquer dos participantes pelo fato de que a realização da leitura como evento social/protocolo verbal em grupo ter tido duração média de 2 horas.

Após esse esclarecimento, ressaltamos que nossa proposta foi observar como a política de indexação da instituição é percebida pelos indexadores e gerentes, para elaboração de um manual de indexação que seja realmente condizente com a sua realidade de trabalho, facilitando, desse modo, a tarefa de indexação considerada tão importante em sistemas de informação.

Os manuais de indexação dos sistemas de informação têm como finalidade uniformizar os procedimentos de indexação realizados pelos indexadores. Sob esse ponto de vista, e nos apropriando das razões apontadas por Chinelato Filho (1997) que justificam a elaboração de um manual, pode-se afirmar então que um manual de indexação em um sistema de informação é importante devido:

- $\quad$ À grande amplitude do sistema, uma vez que sua filosofia é reunir em uma base de dados toda a literatura sobre determinado assunto produzida pelos países cooperantes; 
- À complexidade da tarefa de indexação e à necessidade de uniformização de seus procedimentos por parte de todos os centros cooperantes;

- $\quad$ Ao registro dos procedimentos adotados para que, em caso de novo funcionário, a indexação possa continuar sendo realizada da mesma maneira.

$\bigcirc$ manual de indexação de um sistema de informação constitui sua documentação oficial, está descrito em ordem lógica de etapas a serem seguidas para a análise de assuntos, fornece as regras, diretrizes e procedimentos para o trabalho do indexador e, principalmente, contem os elementos constituintes da política de indexação adotada por um sistema de informação. Portanto, o manual é um dos meios pelo qual a política de indexação de um sistema de informação poderá ser observada. Dessa maneira, pode-se considerar que um manual de indexação deve ser uma condensação de três tipos:

a) Manual de operação ou procedimentos: pois ele deve descrever a atividade de indexação, dar instruções sobre a realização dessa tarefa e proporcionar métodos que possibilitem sua execução de maneira uniforme;

b) Manual de política: o manual deve descrever, de maneira geral e filosófica, as políticas a serem seguidas pelos indexadores no momento da indexação, coordenando, assim, esforços de todos os países cooperantes para que o objetivo do sistema de informação seja alcançado;

c) Manual de organização: deve servir como um repositório das experiências acumuladas dos indexadores mais antigos, a serem aproveitadas para facilitar o treinamento dos mais novos, podendo, com isso, constituir-se num manual de consultas.

Conforme a maneira como os manuais de indexação vêm se apresentando, pode-se afirmar que eles contemplam somente a combinação entre os dois primeiros tipos de manuais: de operação e de política. E é justamente no manual da organização que o conhecimento tácito do indexador deverá se tornar explícito, criando assim novos conhecimentos dentro do sistema de informação e servindo como instrumento de trabalho do indexador e fonte de informação para treinamento de novos profissionais.

Porém, como ter acesso ao conhecimento tácito do indexador?

Lembrando o que os autores Nonaka e Takeuchi ( 1997 ) afirmaram sobre a função da organização no processo de criação do conhecimento, que é fornecer contexto apropriado para facilitação das atividades em grupo e para a criação e acúmulo de conhecimento em nível individual, utilizaremos para investigação do conhecimento tácito dos indexadores uma abordagem metodológica que consideramos adequada a esse fim: a leitura como evento social/protocolo verbal em grupo. 


\section{Subsidios do conhecimento organizacional para a políica de indexação: o uso da leitura como evento social/ protocolo verbal em grupo}

Para obtenção de subsídios do conhecimento organizacional dos indexadores sobre a política de indexação do sistema de informação onde atuam, utilizamos como metodologia a leitura como evento social/protocolo verbal em grupo.

De acordo com Nardi (1999) a origem da prática de leitura como evento social/protocolo verbal em grupo está na metodologia introspectiva do protocolo verbal nos moldes de Ericsson e Simon ( 1987 ), um instrumento de coleta de dados introspectivos originalmente utilizado para coletar informações sobre processos mentais utilizados pelos indivíduos na realização de qualquer tipo de tarefa.

$\bigcirc$ protocolo verbal, de acordo com os referidos autores, fornece informações sobre passos de processamento individual, tais como verbalizações espontâneas, seqüência de movimentos com os olhos, exteriorizando seus processos mentais e mantendo a seqüência das informações processadas.

$\bigcirc$ modelo proposto por Ericsson e Simon (1987) prevê que a informação recém-apreendida pelo processador central é mantida na memória de curto prazo por algum tempo e é diretamente acessível para processamento subseqüente, enquanto que na memória de longo prazo a informação precisa ser recuperada antes de ser relatada. Dessa forma, as informações coletadas em relatos verbais são as recém-apreendidas, diretamente acessíveis para processamento subseqüente.

Nardi (1999, p. 38) apresenta seu ponto de vista sobre as possibilidades de interação social e cultural que se abrem numa leitura. $\bigcirc$ leitor pode interagir não só com o autor do texto, como também com outros leitores que tenham tornado explícitas suas interpretações anteriores do mesmo texto, com outros autores de outros textos que, de alguma forma, se relacionam ao texto sendo lido etc.

Para Bloome (1993), a visão de leitura como processo social e cultural sugere que a leitura possa incluir vários indivíduos interagindo entre si e com o texto ao mesmo tempo; evento em que as pessoas comunicam idéias e emoções, controlam outras pessoas, controlam a si próprias, alcançam objetivos sociais tais como: estabelecer ou reforçar relações sociais; posicionar-se socialmente, externar angústias, objetivos esses que podem tornar-se mais importantes do que atribuir significado ao texto.

A nossa opção pela utilização da leitura como evento social/protocolo verbal em grupo deve-se principalmente ao fato de que esta metodologia possibilita a explicitação do conhecimento organizacional dos indexadores, o que subsidiará a política de indexação revelando aspectos do sistema de informação importantes para a indexação de documentos.

Realizamos duas coletas de dados com indexadores de dois diferentes contextos: de bibliotecas universitárias, que indexam para organização e acesso de seu próprio acervo bibliográfico (área temática direito) e bibliotecas universitárias com indexação vinculada a um sistema de informação de âmbito internacional (Sistema de Informação Especializado em Odontologia - SIEO).

A seguir, apresentamos os subsídios do conhecimento organizacional discutidos pelos indexadores durante a leitura como evento social/protocolo 
verbal em grupo:
a) Automação de bibliotecas;
b) Avaliação de serviços/Usuários;
c) Avaliação do Sistema de Informação Especializado em Odontologia;
d) Capacitação do usuário;
e) Critérios para indexação de periódicos;
f) Formação continuada do indexador;
g) Linguagem/terminologia;
h) Manual de indexação;
i) Procedimentos para indexação;
j) Recursos humanos e financeiros;
k) Softwares / Sistema de Informação Especializado em Odontologia;
I) Valorização profissional do indexador.

Sobre o conhecimento do indexador, verificamos que, de maneira geral, as preocupações dos indexadores são as mesmas: o usuário, a linguagem documentária, o serviço de referência, entre outras. No entanto, de acordo com seu contexto de trabalho, algumas preocupações ficam mais latentes:

a) Indexadoras da biblioteca universitária vinculada ao SIEO:

- $\quad$ as maiores dificuldades relatadas estão na tradução dos termos identificados durante a indexação para os descritores da linguagem documentária, devido à falta de atualização que acompanhe as mudanças na área de odontologia, e nos softwares utilizados. Como os núcleos básicos estão subordinados ao sistema de informação maior, no caso o Centro Coordenador do SIEO, que, por sua vez, está subordinado à BIREME, essas dificuldades são agravadas pois as soluções não dependem dos núcleos básicos e, sim, de mudanças políticas. $\bigcirc$ que ocorre, muitas vezes, é que os núcleos básicos, por meio da experiência de seus indexadores, encontram soluções para suas dificuldades que não são passadas para outros núcleos. Isso ocorre não por má vontade dos núcleos;

- observa-se uma falta de comunicação efetiva entre a rede em que a maior prejudicada é ela própria através de seus indexadores, gerentes e, principalmente, os usuários; 
- foram mais específicas em relação a problemas inerentes à indexação.

b) Indexadoras da biblioteca universitária que não faz parte de um sistema de informação:

- a maior dificuldade está relacionada com a falta de um grupo de apoio, alguém para trocar experiências sobre o serviço de indexação. Consideramos que esse aspecto está relacionado à falta de estabelecimento de uma política de indexação que permeie todo o processo da indexação. Além disso, elas demonstraram grande preocupação com os usuários;

- $\quad$ apresentaram problemas enfrentados durante a realização da indexação, porém de forma mais geral.

Observando os turnos de análise, notamos que a recorrência e a contundência de determinados assuntos são resultados do contexto de trabalho das indexadoras. No entanto, observa-se que os problemas existem independentemente do tamanho da biblioteca, sendo este mais um aspecto a ser considerado para o estabelecimento de uma política de indexação.

Todas as participantes apresentaram algumas soluções para os problemas relatados, tais como: capacitação do usuário para melhor utilização das bases de dados; sintonia entre os serviços de indexação e referência para melhor adequação da terminologia empregada; avaliação pessoal da indexação por meio de comparações entre diferentes serviços de indexação, consulta ao especialista para melhor utilização dos termos, entre outras.

Nota-se, portanto, que os indexadores criam conhecimentos novos, por meio da experiência de cada um. No entanto, esse conhecimento, que ainda é tácito, inerente a cada indivíduo, se não for documentado, expresso de alguma maneira como, por exemplo, um manual de indexação, não se torna explícito, dificultando, assim, a geração de novos conhecimentos por parte do sistema de informação.

Essa metodologia proporcionou troca de informações e experiências o que, segundo as indexadoras, não ocorria de maneira satisfatória. Além disso, retomando o que Nonaka e Takeuchi (1997) propõem a respeito da criação de novos conhecimentos, pudemos proporcionar um momento para atividades em grupo e para a criação e acúmulo de conhecimento em nível individual.

$\bigcirc$ grande investimento do sistema de informação deve ser feito no indexador por meio de treinamento constante, formação continuada e grupos de estudos, uma vez que sejam relatadas deficiências na formação acadêmica sobre indexação e a falta de grupos para discussão a respeito do tema. Não podemos esquecer, conforme os resultados da leitura como evento social/protocolo verbal em grupo, que, quem possui o conhecimento sobre a indexação, é o indexador e somente ele poderá iniciar e dar continuidade aos processos de construção de novos 
conhecimentos sobre a indexação e, consequentemente, sobre sua política, dentro do sistema de informação. Nota-se que a reunião das indexadoras para discussão de um texto resultou em trocas de experiências e soluções práticas para seu trabalho não encontradas em manual algum.

É necessário que tanto os grandes sistemas de informação quanto bibliotecas que não estão vinculadas a qualquer sistema tenham a preocupação em documentar tudo aquilo que é criado em sua organização. Porém, mais necessário ainda, é a criação de redes de comunicação eficientes entre os indexadores, para que haja o compartilhamento de conhecimento, tomando o indexador como fonte de informação para o início da espiral da construção de novos conhecimentos pelo e para o sistema de informação, resultando até mesmo em um manual de indexação mais eficiente. Porém, não nos esquecendo que o indexador sempre estará à frente do manual, com o seu conhecimento.

A este respeito, considerando a importante função do indexador na formação da política de indexação de um sistema de informação, sugere-se um novo aspecto a ser incorporado aos elementos de política de indexação descritos por Carneiro (1985) e Foskett (1973):

- consulta do indexador: verificar junto ao indexador as dificuldades enfrentadas durante a realização de seu serviço e as soluções encontradas por meio de sua experiência para que possa servir de subsídio para atualização do manual de indexação.

\section{Teorias e práticas de ensino de política de indexação na perspectiva do conhecimento organizacional}

Tendo em vista os subsídios identificados por meio da leitura como evento social/protocolo verbal em grupo sobre o conhecimento organizacional de política de indexação dos indexadores de sistemas de informação, pretendemos finalizar este trabalho com algumas propostas práticas para o ensino de política de indexação dirigidas a alunos de graduação e pós-graduação, além de profissionais que já atuam no mercado de trabalho, utilizando para isso o próprio conhecimento organizacional do aluno.

Dessa maneira, pretendemos divulgar a importância do estabelecimento de uma política de indexação e contribuir, de maneira prática, com a área de biblioteconomia, em especial, a indexação, apresentando o curso à distância Política de indexação em sistemas de informação realizado com bibliotecários indexadores das universidades estaduais paulistas que fazem parte do Sistema CRUESP/Bibliotecas: Universidade de São Paulo (USP); Universidade Estadual Paulista (UNESP) e Universidade Estadual de Campinas (UNICAMP).

Com a duração de cinco semanas, o curso tem a seguinte ementa e objetivos: 
Ementa: a política de indexação enquanto decisão administrativa estratégica para otimização de serviços e racionalização de processos em sistemas de recuperação da informação: sua função e metodologia no âmbito de sistemas de recuperação da informação.

Objetivos:

- Demonstrar a importância do estabelecimento de uma política de indexação para o sistema de recuperação da informação.

- Familiarizar o profissional com os elementos de política de indexação e com os manuais de indexação.

- Conscientizar o profissional sobre a importância do indexador para o desenvolvimento da política de indexação

Os módulos, apresentados semanalmente, foram baseados na dissertação de Rubi (2004) e estruturados tendo em vista uma seqüência lógica de conhecimento que resultasse em um produto final: a elaboração de um manual de indexação.

a) Módulo I: $\bigcirc$ contexto administrativo de bibliotecas universitárias e seu papel na socialização do conhecimento:

- $\quad$ enfoque foi feito a partir do contexto em que se encontra a biblioteca universitária, seus aspectos administrativos e sua função enquanto agente da socialização do conhecimento, principalmente na era da informação digital (FUJITA, 2005).

b) Módulo 2: A cultura organizacional na gestão de conhecimento:

- Apresentamos os elementos que constituem a cultura organizacional de uma organização (TAVARES, 1996; TAMAYO, 1998) e os trouxemos para a realidade das bibliotecas, verificando sua importância e influência na rotina de trabalhos dos indexadores.

c) Módulo 3: Elementos para uma política de indexação em perspectiva gerencial de sistemas de informação:

- Demonstramos a importância do estabelecimento de uma política de indexação para bibliotecas e apresentamos os elementos constituintes dessa política na visão de autores como Carneiro ( 1985$)$ e Guimarães (2000).

d) Módulo 4: Observação de procedimentos de indexação e do conhecimento organizacional com aplicação de Protocolo Verbal;

- Apresentamos a metodologia de coleta de dados introspectivos nos moldes de Ericsson e Simon (1987) e Nardi ( 1999 ) para identificação de procedimentos de indexação e do conhecimento organizacional sobre política de indexação. 
e) Módulo 5: A política de indexação e elaboração do manual de indexação

- $\quad$ o enfoque foi sobre os tipos de manuais existentes em uma organização, suas formas e funções, a apresentação dos manuais de indexação de sistemas de internacionais de informação e, principalmente, como fazer do manual de indexação uma ferramenta de trabalho eficaz para o indexador e a biblioteca.

Ao final de cada módulo foi solicitado um exercício sobre o tema proposto. Para solução de dúvidas e esclarecimentos, contamos com a ferramenta chat em que a professora teve a possibilidade de se reunir uma vez por semana com os alunos para debate e solução de dúvidas. Além disso, um momento importante para o curso foi uma aula presencial.

Como visto anteriormente, além da leitura como evento social/ protocolo verbal em grupo, a política de indexação pode ser observada e avaliada por meio da análise dos manuais de indexação e da aplicação de questionários a bibliotecários dos sistemas de informação. Por isso, esse tipo metodologia pode se apresentar como um exercício para a observação dos elementos de política e sua importância para o sistema a que serve, como veremos a seguir.

Atualmente, alguns manuais de indexação estão disponíveis na Internet, como por exemplo, o da BIREME3, o do AGRIS4, o do ERIC5, o que facilita $O$ acesso às informações sobre a política de indexação desses sistemas de informação. $\bigcirc$ exercício, que pode ser realizado individualmente ou em grupo, consiste na busca desses manuais de indexação na Internet e na sua análise quanto ao formato (disposição das informações, layout, facilidade de manuseio) e ao conteúdo, levando-se em consideração os elementos que, por definição de Carneiro (1985) e Guimarães (2000), compõe a política de indexação dos sistemas de informaç̧ão. A seguir, formulase um quadro comparativo desses elementos explicitando as características de cada um dos sistemas de informação e gerando uma discussão a respeito da necessidade e importância de uma política de indexação bem estabelecida.

Posteriormente, solicita-se a elaboração de uma política de indexação para uma biblioteca determinada, lembrando que este documento deverá conter os elementos de política de indexação pertinentes à realidade da biblioteca escolhida. No caso de alunos que não atuam em qualquer tipo de sistema de informação, esse exercício pode ser realizado com a colaboração de um bibliotecário que atue na área por meio de estudo de caso, entrevistas e/ou questionários. Alunos que já atuam em algum sistema de informação, independentemente do setor, pode ser elaborado (ou aperfeiçoado) um manual para a própria instituição, onde o bibliotecário tem maior facilidade de acesso às informações, além de constituir sua realidade de trabalho.

Realizamos as duas experiências com êxito em duas instituições distintas com grupos de alunos de graduação do curso de biblioteconomia que ainda não atuam na área e alunos bibliotecários atuantes de pósgraduação stricto senso em indexação.

No caso dos alunos de graduação, solicitou-se a elaboração da política de indexação para uma determinada biblioteca. Houve a utilização de entrevistas para obtenção dos elementos de política de indexação, 
além do histórico da instituição.

Para os alunos do curso de especialização, foi solicitada a análise comparativa de manuais disponíveis na Internet e, a seguir, a elaboração de um manual de indexaçã̃o com o histórico da instituição onde trabalham, os elementos de política de indexação e, além disso, a metodologia utilizada para a realização da indexação, uma vez que esse serviço era executado por eles.

Outro tipo de exercício diz respeito à avaliação da política de indexação em que se solicita aos alunos uma avaliação da política de indexação do sistema de informação em que trabalham. Neste caso, o exercício foi realizado com bibliotecários que fazem parte do Sistema de Bibliotecas das Universidades Estaduais Paulistas (CRUESP/BIBLIOTECAS) e que atuam no processamento técnico, especificamente, no serviço de indexação e a conscientização dos profissionais em estabelecer uma política de indexação.

Além de identificar e avaliar a política de indexação de sistemas de informação, há, também, a possibilidade de se verificar, por meio de questionário, a política de indexação adotada por serviços de análise de bibliotecas. Nossa experiência foi a aplicação de questionário aos gerentes de duas bibliotecas universitárias da área de medicina e educação que realizam indexação de artigos de periódicos em base de dados local. Com isso objetivou-se conhecer o profissional responsável pela indexação nesta base de dados local; verificar quais os critérios utilizados para selecionar os periódicos a serem indexados, além do software e da linguagem documentária utilizada; tomar conhecimento sobre a existência de um manual de serviço e a periodicidade de atualização da base de dados.

Outro tipo de questionário pode ser elaborado tendo como objetivo observar o perfil do indexador e o conhecimento que este profissional tem a respeito da política de indexação presente no seu local de trabalho. Neste caso, o questionário foi direcionado a indexadores que trabalham em bibliotecas universitárias que fazem parte de um sistema de informação integrado na área de odontologia. Desse modo, objetivou-se observar os procedimentos de indexação; verificar em que medida o manual de indexação auxilia $\circ$ indexador minimizando suas dificuldades durante o processo de indexação; conhecer sua opinião sobre o manual e a política de indexação.

\section{Considerações finais}

Diante desses exemplos práticos observamos que seus resultados demonstraram a importância de se estabelecer a política de indexação, as características e diferenças entre vários tipos de sistemas de informação e por quê a indexação deve ser analisada do ponto de vista administrativo do sistema, uma vez que os resultados da indexação, e de sua política, serão observados na recuperação da informação.

Consideramos que o indexador é ponto de partida para a geração do conhecimento organizacional sobre política de indexação dentro dos sistemas de informação onde atua e este é o motivo principal pelo qual o indexador deve ser valorizado.

Uma das formas de valorização desse profissional seria o investimento na sua educação constante e permanente, seja em cursos de pós-graduação 
ou em cursos de atualização profissional.

Tendo em vista as constantes mudanças nas áreas do conhecimento que o bibliotecário deve acompanhar e que refletirá no seu modo de indexar, é preciso que a atuação profissional também mude com o respaldo da teoria e do próprio conhecimento organizacional do indexador que deverá ser aproveitado na espiral de geração de novos conhecimentos para a instituição. Além disso, não podemos nos esquecer daquele profissional que está sendo formado pelas escolas de biblioteconomia. Quais estão sendo as práticas adotadas para o ensino de indexação e política de indexação na graduação? Esta questão certamente influenciará a prática profissional desse profissional no mercado de trabalho.

Assim, consideramos importante e necessária, a recomendação de novas práticas de ensino que compreendam tanto aquele profissional que ainda está em formação quanto aquele que já atua em sistemas de informação.

\section{The teaching of indexing policy procedures in the perspective of organizational knowledge. a proposal of a program for distance education for librarians}

The indexing policy must be formed by strategies that allow the achievement of the information retrieval system goals. The basic function of the indexer is to understand the document making a conceptual analysis that represents its content appropriately. Using the reading practice as a social event/verbal protocol in groups, the aim of this paper is to contribute with the literature on indexing policy, and to present proposals of teaching indexing policy to the graduation and post-graduation students, besides an experience of distance education aiming at the librarian education on service. The outcome demonstrated that the methodology may be used by information systems in order to access the knowledge of the indexer. The conclusion is that the indexer must be the investment target of the information systems, and to the latter it is suggested that the experience of the indexer should also be used as parameter for indexing policy.

Key-words: Indexing policy; Indexer; Indexing manual; Information retrieval system; Reading as social event/verbal protocol in groups; Organizational knowledge; Practice of education in indexing policy; Distance education.

\section{Referências}

BLOOME, D. Necessary indeterminacy and the microethnographic study of reading as a social process. JournalofResearch on Reading, v. 16, n. 2, p. 98-111, 1993.

BLOOME, D. Reading as a social process. Advances in Reading/Language Research, v. 2, p. 165-195, 1983.

CARMEIRO, M. V. Diretrizes para uma política de indexação. Revista da Escola de Biblioteconomia da lfFMG, Belo Horizonte, v. 14, n. 2, p. 221-241, set. 1985. 
Learning. Clevedon: Multilingual Matters, 1994. p. 148-156.

CHIWELATO FHLHO,J. O\& M integrado à informática.7. ed. Rio de Janeiro: LIC, 1997.

CUBILLO, J. Cambio y continuidad en las organizaciones de gestión del conocimiento. DataGramaZero, v. 1, n. 4, ago. 2002. Disponivel em: < http:/l www.dgzero.or/ago00/Art_02.htm>.Acesso em 5 dez.2002.

ERICSSON, K.A.; SIMON, H.A. Verbal reports on thinking. In. FAERCH, C.; KASPER, G. (Ed.). Introspection in secondlanguage research. Clevedon: Multilingual Matters, 1987.

FOSKETI, A. C. A abordagem temática da informaḑão. São Paulo: Polígono, 1973.

FUJITA, M. S. L. A biblioteca digital no contexto da gestão de bibliotecas universitárias: análise de aspectos conceituais e evolutivos para a organização da informação. In: EMCONTRO NACIONAL DE CIÊMCIA DA INFORMAÇ̃̃̃o, 6., 2005, Salvador. Anais... Salvador: UFBA, 2005. Disponivel em: < http:// www.cinform.uffba.br $>$.

FUJITA, M. S. L. Leitura em análise documnentária. Marilia: UNESP;, CWP q, 1999. Relatório parcial de pesquisa.

FUJIT, M. S. L. A Aeitura documentária do indexador.aspectos cognitivos e lingüisticos influentes na formação do leitor profissional. 2003. 321 T. Tese (LivreDocência em Análise Documentária e Linguagens Documentárias Alfabéticas) - Faculdade de Filosofia e Ciências, Universidade Estadual Paullista, Marilia, 2003.

GUUMARÃESS, J.A. C. Políticas de análisis y representación de contenido para la gestión del conocimiento en las organizaciones. Scire,Zaragoza, v.6, n. 2, p. $48-50$, jul./dic. 2000.

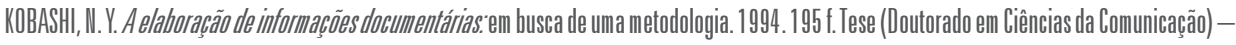
Escola de Comunicação e Artes, Universiddade de São Paulo, São Paulo, 1994.

LAMCASTER, F. W. Indexą̧ão e resummos. teoria e prática. Trad. Antonio Agenor Briquet de Lemos. Braślia: Briquet de Lemos, 1993.

NARDI, M. I. A. A metáf́rora e a prática de leitura como evento social. instrumentos do pensar a Biblioteconomia do futuro. 1999. 272 f. Tese (Douttorado em Lingüistica Aplicada e Estudos da Linguagem) - Programa de Lingǘstica Aplicada e Estudos da Linguagem, Pontificia Universidade Católica, São Paulo, 1999.

NONAKA, I.; TAKEUCHI, H. Teoria da criação do conhecimento organizacional. In.: NONAKA, I.; TAKEUCHI, H. Crią̧äã de conhecimento na empresa.como as empresas japonesas geram a dinâmica da inovação. Rio de Janeiro: Campus, 1997. p. 61-102.

POLANYI, M. The tacit dimension. Garden City, II.Y.: Doubleday, 1966

RUBI, M. P.: FUJITA, M. S. L. Flementos de política de indexação em manuais de indexação de sistemas de informação especializados. Perspectivas em Ciênncia da Informação, Belo Horizonte, v. 8, n. 1, p. 66-77, jan.jun. 2003.

RUBI, M. P. A politicica de indexą̧ãa na perspectiva do conhecimentto organizacional.2004. 135 f. Dissertação (Mestrado em Ciência da Informação) Faculdade de Filosofia e Ciências, Universiddade Estadual Paulista, Marilia, 2004.

TAMAYO, A.Valores organizacionais: sua relaçãa com satisfação no trabalho, cidadania organizacional e comprometimento afetivo. Revista de Admininstração, São Paulo, n. 3, p. 56-63, jul./set. 1998.

TAVARES, F. P. A cultura organizacional como um instrumento de poder. Caderno de Pesquisas em Admininstração, São Paulo, v.1, n.3, jul./dez. 1996.

VYGOTSKY, L.S. The genesis of higher mental functions. In: WERTSCH, J.V. (Ed.). The concept of activity in Sovietpsychology. New York: Sharpe;, Armonk, 1981. 